\title{
The Creeps as a Moral Emotion
}

\author{
JEREMY FISCHER \\ University of Alabama in Huntsville
}

RACHEL FREDERICKS

Ball State University ${ }^{1}$

\begin{abstract}
Creepiness and the emotion of the creeps have been overlooked in the moral philosophy and moral psychology literatures. We argue that the creeps is a morally significant emotion in its own right, and not simply a type of fear, disgust, or anger (though it shares features with those emotions). Reflecting on cases, we defend a novel account of the creeps as felt in response to creepy people. According to our moral insensitivity account, the creeps is fitting just when its object is agential activity that is insensitive to basic moral considerations. When, only when, and insofar as someone is disposed to such insensitivity, they are a creep. Such insensitivity, especially in extreme forms, raises doubts about creeps' moral agency. We distinguish multiple types of insensitivity, respond to concerns that feeling the creeps is itself objectionable, and conclude with a discussion of epistemic issues relating to the creeps.
\end{abstract}

Keywords: creepiness, the creeps, emotion, moral agency, moral insensitivity

\section{Introduction}

In the 2017 film Get Out, the black protagonist, Chris Washington (Daniel Kaluuya), visits the secluded family estate of his white romantic partner, Rose Armitage (Allison Williams). Although the Armitages, who present themselves as Obama-supporting liberals, initially treat Chris with some warmth, they plan to kidnap him and implant into his body the brain of an ailing white acquaintance, who bought the privilege at auction. This acquaintance will thereby gain control over Chris's body, though Chris will, horrifyingly, retain consciousness.

1. The authors of this paper are equal co-authors, listed alphabetically.

Contact: Jeremy Fischer <jeremy.fischer@uah.edu> and Rachel Fredericks <rlfredericks@bsu.edu> 
Chris discovers their plan and that they have already given multiple white people control over kidnapped black people's bodies. He then struggles to escape.

The film arouses fear, moral disgust, and moral outrage, but responding only in those ways neglects one of its central elements: creepiness. Indeed, highlighting the creepiness of the Armitages' project is key to showing how deeply immoral it is. The film resonates with audiences, possibly (hopefully) because it awakens or validates emotional understanding of the creepiness of white supremacy.

Portrayals of racism in American popular culture tend to focus on arousing indignation, anger, fear, disgust, contempt, guilt, shame, or pity. But instances of American racism - from genocide and internment to slave auctioning, from separating enslaved families to public lynchings and nonconsensual medical trials, and from disproportionate police violence against people of color to racial segregation - do not warrant only those emotions. Because these racist practices are so creepy, they also make fitting an emotion known as "the creeps." ${ }^{2}$

The creeps is also, and more familiarly, a fitting response to creepy misogynistic practices, like stalking, flashing, and public masturbation. Indeed, the noun "creep" is often, even primarily, used to refer to people who do such things.

Reflecting on creepiness after watching Get Out motivates our asking precisely what creepiness is and when feeling the creeps is fitting. That is, when does this emotion accurately represent its objects? Furthermore, are there conditions under which we should not feel the creeps, even if it would be fitting? ${ }^{3}$ As we discuss in Section 6, though feeling the creeps tends to be especially appropriate when creepy things' strangeness, ambiguity, or unfathomability is salient, it is sometimes reasonable, or even imperative, that we feel other emotions toward such objects instead of the creeps.

Contemplating these questions has led us beyond the familiar but narrow conception of the creeps as a response to relatively insignificant (though distressingly ambiguous or unpredictable) social or moral transgressions. While intuitions may differ, we argue that the creeps can also be accurately directed at monstrous and unfathomable moral insensitivity. After all, central to the experi-

2. The creeps is in the same family of emotions as the willies and the heebie-jeebies; however, as Tyler Doggett pressed us to see, the latter two may be less serious, or even trifling feelings. For simplicity, we focus on the creeps and the evaluative property that it is about, namely, creepiness.

3. In what follows, we assume that the creeps is intentional (in being directed at or about something), phenomenological (in being a felt bodily experience), and epistemological (in being evaluable as more or less accurate or justified) (Deonna \& Teroni 2012). However, we do not assume any particular theory of emotions (such as perceptualism, judgmentalism, etc.). In our view, what distinguishes such theories is largely a matter of which feature is portrayed as central or fundamental, which is irrelevant to our purposes here, namely: to identify and defend (i) an account of when (not how) the emotion accurately represents its intentional objects, and (ii) a partial account of when feeling the emotion is prudentially and morally appropriate. On the distinction between emotional fittingness and other kinds of appropriateness, see D'Arms and Jacobson (2000). 
ence of the victims of many serious crimes and moral wrongs is feeling that the perpetrator is creepy as hell. Ignoring this distorts our understanding of morality and the seriousness of some mistreatment.

Moral philosophers, however, generally overlook the creeps, instead discussing how immoral activity can cause or make fitting anger, disgust, indignation, blame, guilt, shame, or remorse. ${ }^{4}$ We develop an account of creepiness that vindicates victims' and their advocates' experiences and shows why the creeps is an important moral emotion in its own right.

Indeed, since, as we argue, people's creepiness is an insensitivity to basic moral considerations, and since overlooking creepiness is itself defeasible evidence of moral insensitivity, failure to feel the creeps sometimes provides evidence that one is (somewhat) creepy. So, inculcating the disposition to properly feel the creeps is imperative, though rarely recognized as such.

We begin, in Section 2, by introducing five paradigm cases of the creeps and identifying seven important features of the emotion that require explanation. In Section 3, we motivate our account with negative arguments against the view that the creeps is simply a type of fear, disgust, or anger. Rather, as we argue positively in Section 4, the creeps is a distinct emotional response to moral insensitivity. In Section 5, we distinguish moral insensitivity from other types of insensitivity. In Section 6, we consider objections to our account and sketch an account of the conditions under which feeling the creeps is morally and prudentially appropriate. The remaining sections are more discursive, since, to our knowledge, ours is the first philosophical account of the creeps, and discussion is needed to motivate future research. So, in Section 7, we highlight epistemic obstacles to identifying creepiness and issues relating to communication about the creeps. In Section 8, we conclude by raising further questions about the creeps, including why it so often occurs in contexts of oppression.

\section{Features of Creepiness and the Creeps}

Consider some cases:

Statue: Entering a museum, you unexpectedly confront a statue so lifelike that you suspect it is actually a person. ${ }^{5}$ You cannot help but imagine it moving. You flee, trying not to visualize it again.

4. The only extended treatment of creepiness we know of is Kotsko's (2015) Freudian analysis of pop culture artifacts.

5. Consider Duane Hanson's Woman Eating (1971): https://americanart.si.edu/artwork/wom an-eating-75123. 
Horror Movie: Some teenagers watch a horror movie about a weirdo who violently preys on innocent protagonists. He is just predictable enough for the audience to know when evil is imminent, but not enough to be easily identified, captured, or avoided by the protagonists, nor for the audience to know what he will do. The narrative, spooky music, visual effects, and darkened theatre make the audience distinctly uneasy.

Bar: A woman at a bar notices a man staring at her. She is not flattered and does not encourage it. Later, she sees him staring again, or still. She pivots, trying to block his vision. Yet he continues. She tries making lively conversation with others, but unable to focus, she wonders if things will escalate to a verbal intrusion, a drugged drink, stalking, sexual assault, mugging, something else, or nothing. Her distress increases.

Subway: You are riding an empty subway car at night. A passenger enters. Despite dozens of clean, empty seats, and for no apparent reason, they sit next to you (making significant bodily contact), without acknowledging you. You tentatively ask if they would mind moving. They slowly, deliberately face you and, grinning, ask if they are making you uncomfortable.

We can also imagine less familiar examples that share key elements with these "classic" cases, like:

Carnists: A vegan goes to a carnival where people are walking around eating the roasted legs of turkeys. Considering their neighbors' happy, shameless gnawing on the charred corpses of sentient animals who were raised in dirty, crowded conditions and slaughtered for profit, the vegan shudders. ${ }^{6}$

One might feel the creeps in any of those cases, which exhibit seven features that any account of the creeps should explain:

1. The creeps resembles fear (or, in extremis, dread or terror).

2. The creeps resembles disgust (or, in extremis, revulsion).

The creeps is an aversive state, not a motivationally inert assessment. Despite some people's enjoyment of fictions about creepiness, attraction to what one

6. We use "carnist," not "carnivore," because (i) "carnivore" is a zoological (not culinary or ethical) term, and (ii) all humans are omnivores, strictly speaking. "Carnist," like "vegan," refers to someone who endorses a particular practice: for carnists, eating certain animals. See Joy (2009). 
feels the creeps about would be unusual.7 The creeps also feels somewhat like fear or disgust. It is not just any felt aversion, though.

3. Part of what is so unnerving about creepiness is the creepy person or object's (apparent) unpredictability or inexplicability.

Aversion to creeps is rarely focused on a specific danger, unlike fear of a vicious neighborhood dog. You often cannot tell exactly how, if at all, a creep plans to or is likely to mistreat you: the options are myriad (McAndrew \& Koehnke 2016; Watt, Maitland, \& Gallagher 2017). ${ }^{8}$ Due to the nebulous quality of creepiness, we may never be able to explain why an encounter with a creep elicited the creeps. 9

Next, consider the noun "creep," as used above. English speakers mark a subtle distinction by using it exclusively for creepy people, while the adjective "creepy" can modify objects, persons, and more. We call a stalker-but not a creepy doll, insect ${ }^{10}$, or institution - "a creep." Feeling the creeps about a person (an apparent creep) involves evaluatively responding to their agency, specifically their moral agency. For aversion to creeps is not based on the same kinds of considerations as aversion to people who have the flu, play the violin badly, make foolish decisions, or have poor table manners. There are no morally innocuous hygienic, aesthetic, prudential, or etiquette creeps - all creeps are moral creeps. Thus,

4. Being a creep is a moral phenomenon; experiencing the creeps toward creepy people involves interpreting them using moral standards.

So, while it is possible to feel the creeps in response to creepy things, we call emotional responses to creepy people the moral creeps. Unless otherwise noted, we use "the creeps" as shorthand for "the moral creeps."

7. Though not impossible: see Rozin, Guillot, Fincher, Rozin, and Tsukayama (2013) on the benign masochism of taking pleasure in feelings like sadness or disgust. See also Menninghaus, Wagner, Hanich, Wassiliwizky, Jacobsen, and Koelsch (2017), and the accompanying thirty-two peer commentaries and authors' response, on enjoyment of negative emotions in art. The paradox of horror is relevant here, but, engagement with fiction and benign masochism aside, when someone seems attracted to something that they find creepy, another motivation probably outweighs the creeps' aversive element. Or maybe they do not feel the creeps at all; perhaps they simply recognize that others find it creepy and enjoy contrarianism.

8. According to the $O E D$, "uncanny," a word for a related phenomenon, originally referred to supernatural influence over physical things, or at least influence beyond one's ken.

9. Thus, we occasionally find eye contact with non-human animals creepy, since their mental activity is sometimes especially inscrutable. In fact, according to the $O E D$, the phrase "heebiejeebies" originates in a 1923 comic strip's depiction of a horse staring at a man, who retorts, "You dumb ox - why don't you get that stupid look offa your pan-you gimme the heeby jeebys!"

10. Etymologically, "to creep" signifies slow, insect-like crawling. 
Although we focus on the moral creeps, some creepy people share a key feature with creepy things: namely, ambiguous or indeterminate agency. While we do attribute agency to them, some creeps strike us as being near the boundary of the community of moral agents - that is, the community of those who are sensitive to the basic considerations that should regulate social activity (Watson 1987). While all creeps are agents, perhaps not all are moral agents; extreme psychopathic creeps may be incapable of governing their activities in accordance with moral reasons. Whether they are inside or outside of it, such psychopathic creeps are near the boundary of this community (but still moral patients, worthy of moral consideration and not to be treated as mere objects). Other creeps are somewhat further inside the boundary that divides moral agents from mere moral patients, but their creepy behavior may still sometimes raise doubts about their moral agency.

Similarly, though for superficial reasons of appearance, life-like dolls and animatronic figures might seem to be agents. ${ }^{11}$ As Statue illustrates, feeling the creeps can involve attributing quasi-agential features to objects. So whereas the agential ambiguity in cases involving creeps concerns their status as moral agents, the ambiguity in cases involving creepy things concerns their status as agents simpliciter. Thus,

5. Paradigmatic creeps include individuals near the boundary of the community of moral agents, such as unrepentant criminal psychopaths, serial killers, and sexual predators.

Such creeps seem (almost) completely insensitive to moral considerations. Feeling the creeps comes easily when such insensitivity is on display, as in video interviews with serial killers like Jeffrey Dahmer or photographs of audiences celebrating public lynchings.

This moral dimension of the creeps, and in particular the significant damage that creeps sometimes inflict on innocent people, suggests a sixth key feature:

6. The creeps closely relates to anger (or, in extremis, outrage or indignation).

The creeps and anger seem to co-occur with some regularity; one can easily imagine victims wishing for revenge or retaliation against the creeps who have creeped them out. Third parties may also feel such emotions on a victim's behalf.

Finally, creeps are heterogeneous:

11. For discussion of the "uncanny valley effect" that life-like faces can generate, see Moore (2012), Mori (1970/2012), and Seyama and Nagayama (2007). 
7. Not all creeps are equally creepy, or creepy in the same patterned way.

Some people are creepy in many situations, toward many people. Other creeps are more discriminating. An account of creepiness should explain and taxonomize these patterns. In practice, of course, determining whether someone is a creep (and if so, what kind) is often quite difficult. More on this in Section 7.

Next, we argue against three plausible accounts of the creeps. After doing so, we revisit horror movies to motivate our own positive account, which appears in Section 4 .

\section{The Creeps and Similar Emotions}

Features (1) and (3), above, might suggest that the creeps is a form of fear about unpredictable danger. This fear-based account plausibly captures the confusion and terror associated with the creeps. However, it fails to capture the moral dimension described in feature (4). For tornados and earthquakes can elicit confusion and terror without being creepy. The creeps' moral dimension requires that it respond to an agent (or at least something somewhat agential). Moreover, it seems that one might fittingly feel the creeps about, for instance, the activity of a deceased or imprisoned person who elicits no fear. (Though even if the creeps always involved some element of fear, it would not follow that it is a form of fear. $)^{12}$

Alternatively, feature (2) might suggest that the creeps is a form of disgust, a response to contaminants. This disgust-based account plausibly explains the creeps' repulsive aspect. However, the creeps, unlike disgust, often involves concern about attack. Unlike most physically disgusting things, people are creepy in virtue of their activity; features of their minds, more than their bodies, elicit the creeps (again, recall feature (4)). Second, concern about physical or social contamination is not necessary for the creeps; for example, Dahmer is creepy even though his cannibalism was not contagious. Third, the disgust-based account fails to explain the unpredictability of creepiness (feature (3)), because paradigmatic disgusting things (elicitors of "core disgust"), like rotten flesh, are highly predictable (Haidt, Rozin, Mccauley, \& Imada 1997; Rozin, Markwith, \& Stoess 1997; Rozin \& Singh 1999; Kelly 2013). Finally, while moral disgust might sometimes be fittingly directed at the flouting of norms against, say, casual littering or academic cheating (Plakias 2018), such morally disgusting activities are not (or need not be) creepy.

Feature (6) might suggest that the creeps is a kind of anger or moral indig-

12. Thanks to Tyler Doggett for suggesting this last point. 
nation about wrongdoing. This anger-based account plausibly explains why the creeps are rightfully directed at serial killers and rapists. However, while the creeps' cold, withdrawing, or shrinking phenomenology resembles that of fear or disgust, it differs strikingly from the hot or expansive phenomenology of anger and indignation. Moreover, the creeps' primary action readiness mode is aversion, but anger's is aggression or antagonism, which requires engagement with the offender (Frijda, Kuiper, \& ter Schure 1989: 220-221; Roseman, Wiest, \& Swartz 1994). Thus, we say that the creeps often co-occurs with anger, but that they do not bear a particularly strong resemblance to each other. And they do not always co-occur. The creeps is sometimes felt toward (and can be a fitting reaction to) ambiguously menacing behavior, even if anger is not felt (and would not be fitting). Consider, for instance, cases involving creeps who have not actually threatened, harmed, or otherwise wronged anyone (like, perhaps, Subway).

Finally, Horror Movie suggests that the creeps might be related to horror. However, many creepy objects of the emotion that Noël Carroll (1987) calls "arthorror" are supernatural-ghosts, werewolves, zombies, vampires, demons, etc. By contrast, the moral creeps responds to thoroughly natural entities.

Nevertheless, the creeps is in one respect importantly like art-horror. As Carroll notes, art-horror represents objects as "categorically interstitial, categorically contradictory, categorically incomplete, or formless" (1987: 55): for example, things that are both living and dead, humanoid and reptile, one individual and another (e.g., Jekyll and Hyde); animals with missing body parts; and gelatinous or vaporous creatures. While the creeps is not primarily directed at biological interstitiality, extreme psychopathic creeps are, we suggest, morally interstitial, incomplete, or disfigured. For example, some of what we (the authors) find creepiest, like anti-Semitic Nazi propaganda, anti-Japanese American propaganda from WWII, and anti-black American propaganda, express views that are as morally disfigured as zombies are biologically disfigured. For they portray their targets as interstitial humans/non-humans to convey the view that some humans (and all non-human animals) lack moral standing. Such views are, simply, insensitive to others' moral standing. Conceiving of the creeps as a form of horror thus makes sense of our remarks about creeps being morally uncanny and somehow near the boundary of the community of moral agents (feature (5)). So perhaps the creeps is a form of moral horror.

Part of Get Out's creepiness, and perhaps art-horror, lies in how the Armitages create hybrid people who literally embody a sort of double consciousness. ${ }^{13}$ But the main creepiness of Get Out lies in the white community's moral disfigurement, which causes them to overlook the dignity, autonomy, and well-being

13. This does not map precisely onto Du Boisian double consciousness. Besides, Du Boisian double consciousness does not makes one a creep; on the contrary, insofar as it enables "second sight," it protects against being creepy. See Du Bois (1903/2007: 3). 
of black individuals (whether by violating their bodily autonomy or through myriad microaggressions). The antagonists are people, yet such creeps that viewers strain to recognize their humanity. If they would do this, what would they not do? Pursuing their goals has a cost-moral debasement-reminiscent of what James Baldwin (1985) termed "the price of the ticket" for admission into the delusional realm of whiteness. The film validates the creeps that racially stigmatized viewers sometimes feel in response to the microaggressions (and worse) that pervade predominately white social spaces. Reflective white viewers must ask themselves: are these antagonists like me, or criminal psychopaths? Or, chillingly, are they both?

\section{The Moral Insensitivity Account}

We have listed central features of the creeps that must be explained and argued that the creeps is not a type of fear, disgust, or anger. Now for our positive account.

We propose that the creeps is fitting just when directed at creepy agential activity. Creepy agential activity, in turn, is activity that is insensitive to basic moral norms, reasons, or values. For brevity, we call such insensitivity "moral insensitivity" or "insensitivity to basic moral considerations." ${ }^{4} 4$ When, only when, and insofar as someone is disposed to moral insensitivity, they are a creep. Call this the moral insensitivity account of the creeps.

What precisely do we mean by "moral sensitivity"? Certainly not moral perfection. One might be morally sensitive and yet commit moral errors for which one is responsible and even blameworthy. For example, sensitivity does not require noticing moral considerations whenever they are relevant, because a sensitive person can be in a complex situation or distracted in a way that makes noticing difficult. Moreover, one might be sensitive to moral considerations that one notices, despite mischaracterizing their nature or significance. Furthermore, sensitivity does not require morally appropriate behavior, because sometimes one notices and properly understands moral considerations, but simply fails at enacting one's evaluation.

Defeasible evidence of moral sensitivity includes noticing, looking out for, or concentrating on a moral consideration; being confused about how to take it into

14. We cannot here provide an account of basic moral considerations, but suggest, provisionally, that a moral consideration is basic just when it fundamentally grounds facts about an action's moral permissibility. Candidates include well-being, being the subject of a life, rational capacity, and the capacity for sympathy and caring relationships. Candidates for non-basic moral considerations include the value of gratitude and of generosity, which seem derivative of more basic moral considerations. Since we cannot settle the matter of which considerations are morally basic here, we also cannot settle all questions about the nature of moral sensitivity. 
account while knowing that one should; acting in implicit or explicit recognition of it; and regretting or feeling guilty that one cannot or does not act on it. Yet although being morally sensitive does not imply that one successfully respects, preserves, or promotes the value to which one is sensitive, such success is defeasible evidence of moral sensitivity.

In our view, one is sensitive to moral considerations just when one recognizes and responds to them in a way that is not egregiously deficient or off base, which is to say: in a minimally reasonable way. By contrast, moral insensitivity is, or reflects, badly mistaken judgments about moral considerations. Metaphorically speaking, morally sensitive people have their moral searchlights aimed in the correct vicinity of considerations, even if imprecise placement or poor illumination leads to imperfect identification of or response to the relevant considerations. They operate within a reasonable margin of error. By contrast, creeps' moral searchlights are significantly off the mark (or, worse, intentionally extinguished). For while creeps do engage in mental activity with respect to moral reasons, they do so appallingly.

Moral sensitivity requires both reasonably successful concept selection (e.g., PERMISSIBILITY, RESPECT, Or CARE) and reasonably successful reference (e.g., to what is actually permissible, respectful, or caring). ${ }^{15}$ Simply using contextually relevant moral concepts does not guarantee moral sensitivity. For one might radically misapply them, like a parent who kills their infant out of a radically misguided view of what virtue requires in their circumstances.

Moral sensitivity also requires reasonably appropriate patterns of attention and perception. For a morally insensitive person might fail to notice how their behavior impacts others; we could call these oblivious creeps. An interlocking dimension of moral sensitivity is reasonable concern or desire. While oblivious creeps might fail to notice their impact on others because they simply do not care sufficiently about others' interests, other creeps do notice the discomfort they cause others, but do not care; we could call these deliberate creeps. ${ }^{16}$

Different kinds of activity matter differently in assessing moral insensitivity. Assuming that action is typically more morally important than thought, an insensitive unexpressed thought may be very bad, as thoughts go, but less bad than an equally insensitive action. Even among actions, there are differentially important aspects that must be considered together to assess overall creepiness. A creepily insensitive, but relatively trivial aspect of an action (like, perhaps, vocal tone) might render the action only slightly insensitive, provided that more important aspects (like, perhaps, motivation) are not insensitive.

This picture of moral sensitivity allows that one might misunderstand the

15. For a similar distinction, see Arpaly and Schroeder (2014: 290).

16. Thanks to Angela Smith for suggesting this distinction. 
precise nature or import of some relevant moral consideration, and so respond inappropriately to it, without being insensitive. It also allows for degrees of insensitivity (and thus of creepiness), since responses might be more or less unreasonable. Get Out's villains are completely, habitually off the moral mark. The creep in Bar is also well off the mark, but much less so (either because he is insensitive to values of lesser importance or because he transgresses the same values to a lesser degree). Moreover, what is unreasonable might vary with context. Fully virtuous people always focus their moral searchlights as they should, and merely decent non-creeps achieve a reasonable approximation of that, given the burdens of moral judgment.

This moral insensitivity account explains the seven central features listed in Section 2 that any adequate account of the creeps must explain. First, our account explains why the creeps resembles fear (feature (1)). For one thing, it is consistent with the earlier claims that they are similar both motivationally and phenomenologically. Furthermore, being the focus of a morally insensitive person's attention - or even just in their vicinity - puts one in a kind of danger. So, the creeps and fear often co-occur. For example, while creeps in bars often insist that their behavior is benign because women can decline their advances or leave, women know that such creeps are occasionally and unpredictably dangerous. If nothing else, such creeps are insensitive to the badness of the fearful discomfort that they reasonably elicit or to the moral norm against needlessly eliciting such discomfort. ${ }^{17}$ Consequently, they lack one barrier to anti-social behavior. This insensitivity provides reason - in addition to their otherwise discourteous and threatening behavior - to avoid creeps even if and when one is not afraid of them.

Our account also explains why the creeps resembles disgust (feature (2)), since moral insensitivity can be morally disgusting, as in cases of racism, mass murder, and gross neglect of the elderly (Haidt et al. 1997: 116). Some speculate that moral disgust involves or causes us to "step back, push away, or otherwise draw a protective line between the self and the threat" (Haidt et al. 1997: 127; see also Plakias 2018: 5462). This is precisely what moral insensitivity calls for (and why Get Out is an apt title of that film). Furthermore, cases of extreme creepiness, like the mutilations in Get Out, can simultaneously be disgusting in a more fundamental, biological sense.

Our account also explains the creeps' relation to anger (feature (6)). Moral insensitivity is neither necessary nor sufficient for moral wrongdoing. One can do wrong, making anger fitting, while being morally sensitive-as, perhaps, in re-

17. Thus, the creep in Bar is not just violating a social norm. As John Draeger argues in a discussion of the creepiness of voyeurism, "because voyeurism remains troubling even in the absence of harm or deceit, we must pay special attention to the ways that complex social conventions can be used to show disrespect for others" (2011: 41). 
sponding to moral dilemmas or when overwhelmed by the burdens of judgment. One can perhaps also be insensitive to some moral consideration, say during idle rumination, without doing wrong - or at least not a wrong worthy of anger. But anger may be fitting when moral insensitivity does violate what we owe to each other, and the creeps may be fitting when wrongdoing is beyond the pale.

Furthermore, and crucially, our account explains why the creeps is not simply a subtype of these three emotions (as argued in Section 3). For the creeps' characteristic intentional object (moral insensitivity) differs from the characteristic intentional objects of fear, disgust, and anger (danger, contamination, and wrongdoing).

Our account also explains features (3), (4), and (5): that creeps' behavior is unpredictable, that creepiness is a moral phenomenon, and that heinous criminals are paradigmatic creeps. Creeps' moral insensitivity prevents them from properly attending to basic moral considerations. Thus, in their presence, one must guard against behavior that would strike morally sensitive people as unfathomable. ${ }^{18}$ Heinous criminals are paradigmatic creeps because we regard them (rightly or wrongly) as paradigmatically morally insensitive. In contrast, the stereotypical embezzler or burglar strikes us (rightly or wrongly) as morally misguided and culpable, but not insensitive to moral considerations.

What about the range of different types of creeps alluded to in our discussion of feature (7)? Let us now distinguish four types (we discuss an additional way to taxonomize creeps in Section 5). A creep simpliciter is largely and indiscriminately insensitive to basic moral considerations. Insofar as psychopaths are so insensitive, feeling the creeps toward psychopaths is the emotional response to them par excellence.

Domain-specific creeps are largely insensitive to basic moral considerations in some social domain, but are sensitive to moral considerations (perhaps even the same ones) in others. For example, Walter White, early in the television show Breaking Bad, does awfully creepy stuff in his business dealings during his initial moral descent to total creepiness, though perhaps not (yet) in his family life. ${ }^{19}$

Sectarian creeps are insensitive to basic moral considerations except regarding fellow members of their social group. So, a sectarian creep might disregard moral considerations except as they relate to those who share their social identity. ${ }^{20}$

18. As Bernard Williams observes, "One does not feel easy with the man who in the course of a discussion of how to deal with political or business rivals says, 'Of course, we could have them killed, but we should lay that aside right from the beginning.' It should never have come into his hands to be laid aside" (1985: 185).

19. Categorizing people as domain-specific creeps requires extra caution, since apparent domain-restricted concern can be illusory. Someone who claims to love J. S. Bach's music, but is indifferent to it whenever played expertly by buskers, might love high society concerts, not Bach.

20. See Lifton (2000) on doubling, which bifurcates the self, enabling people to contribute to sectarian atrocities while retaining a positive self-conception. 
Single-value creeps are insensitive to one moral value, such as autonomy, across domains. This might be the case with anti-social creeps, who are insensitive to others' discomfort and how their behavior might reasonably be perceived as threatening or offensive. ${ }^{21}$

However, due to their moral insensitivity, all creeps are disposed to activity that raises reasonable doubts about their ability or willingness to live with at least some others on moral terms. Consequently, their status as members of the community of moral agents may be doubtful or precarious; they are certainly moral patients, and certainly agents, but their moral agency may be questionable, underdeveloped, or non-existent.

Here, in summary, is our proposal. The emotion of the moral creeps can be directed at either activities (representing them as creepy) or people (representing them as creeps). The creeps about some activity is fitting just when such activity is morally insensitive. The creeps about some person, on the other hand, accurately represents its intentional object as a creep just when:

1. It is directed at an agent;

2. In response to their general (but not necessarily total) dispositional insensitivity to moral considerations:

a. Across the board (a creep simpliciter),

b. Within some social domain (a domain-specific creep),

c. As they pertain to some class(es) of persons (a sectarian creep), or

d. Regarding one basic moral value (a single-value creep); and

3. Their insensitivity calls into question or makes precarious their membership in the community of moral agents.

Condition (1) precludes non-agential objects, like statues, from being creeps (though not from being creepy in a non-moral way). Since moral insensitivity reflects badly mistaken judgments about moral considerations, condition (2) precludes agents who are incapable of moral judgment (like, perhaps, crocodiles) from being creeps. However, even extreme creeps simpliciter with seriously impaired moral capacities are still capable of moral insensitivity insofar as they grasp moral concepts or can recognize moral distinctions. Condition (3) requires that creeps' moral insensitivity be sufficiently significant to call into question their willingness or capacity to accept the basic terms of the moral community (to borrow language from Watson 1987).

That moral insensitivity requires the capacity for moral judgment might seem paradoxical. For thermometers need not be capable of making judgments about air pressure to be insensitive to it. However, the analogy is misleading. Moral in-

21. Thanks to Angela Smith for encouraging us to highlight such creeps. 
sensitivity is a failure, not an absence, of judgment. Unlike thermometers, creeps are agents. Agents, moral or otherwise, act for reasons. Agents' activities therefore reflect judgments about reasons. Unlike a thermometer's insensitivity to air pressure, morally insensitive activity reflects judgments about reasons that one can, in principle, be asked to defend. Such activity even includes not thinking about moral considerations, at least insofar as such omissions reflect egregious judgments about such considerations. However, while we maintain that moral insensitivity requires badly mistaken judgments about morality, we recognize that further clarification is needed.

\section{Types of Insensitivity}

To dispel a potential misinterpretation, we must distinguish between moral and descriptive insensitivity. For it might seem that we are implying, for instance, that neuroatypical people who have difficulty identifying others' discomfort are thereby creeps. We are not. Contrary to widespread misinformation about autistic and other neuroatypical people, they generally recognize the moral badness of others' discomfort (and other basic moral considerations) and want to respond appropriately; they sometimes simply have difficulty reading the relevant cues or processing relevant information. Being insensitive to certain descriptive facts, such as that someone feels embarrassment or that shifting the topic of conversation would mitigate that embarrassment, provides no evidence of creepiness if there are adequate non-moralistic explanations of it, such as impairment in simulating, or applying one's theory of mind to infer, another's mental states. Only moral insensitivity constitutes creepiness. Insofar as they are generally morally sensitive, neuroatypical people are generally not creeps, though some people sometimes unfittingly feel the creeps toward them. ${ }^{22}$

Because social norm violations are creepy when and only when they mediate moral insensitivity, and because moral insensitivity requires badly mistaken moral judgments, morally innocuous violations of social norms are not creepy. Some violations of social norms, far from being creepy, merely reflect cultural ignorance, say, of certain gestures' meaning. Compare the original Subway case to the following variation:

22. In this section, we are discussing passive, innocuous descriptive insensitivity. However, there are forms of descriptive insensitivity that are neither passive nor innocuous: forms of motivated ignorance readily come to mind. By contrast, there are no passive or innocuous forms of moral insensitivity (see Section 4). For a discussion of active descriptive insensitivity that bears on moral insensitivity, see Woomer (2019) on "agential insensitivity." 
Excused Subway: Someone sits beside you on an empty train, giving you the creeps. You ask if she would mind moving. Confused and alarmed, she apologizes, explaining that in her distant small town, travelers customarily accompany each other. She apologizes again and changes seats.

Only in the original version of Subway does violation of social norms mediate moral insensitivity. For only then does social norm violation express insensitivity to the moral norm against causing or taking pleasure in the gratuitous nonconsensual discomfort of others. Excused Subway involves mere (unmotivated) ignorance of social norms. Such ignorance does not reflect unreasonable mental activity regarding moral considerations, provides no evidence of moral insensitivity, and is not creepy. ${ }^{23}$ The social norm violation is excused, but there is no moral insensitivity or wrongdoing to be excused.

Consider another Subway variation:

Justified Subway: As in the other versions of Subway, you gather your courage and ask the rider if he would mind moving. He apologizes, saying that schoolmates were bullying him on the platform and all he could think to do was lie, telling them that he saw a family friend-you. He asks whether you would mind his staying with you for a bit.

The social norm violation here is justified, so the rider's moral judgment is not mistaken, and the creeps is not fitting. You should stop feeling the creeps after hearing their story. ${ }^{24}$

Finally, it is useful to distinguish two kinds of moral considerations to which one might be insensitive. On the Aristotelian assumption that practical reasoning employs major and minor premises, "major premise moral insensitivity" (e.g., insensitivity to the universal claim that disrespecting autonomy is wrong) differs from "minor premise moral insensitivity" (e.g., insensitivity to the particular claim that my act disrespects Barbara's autonomy). Both kinds of considerations are morally imbued, so insensitivity to either is moral insensitivity. Major-premise creeps are not always worse than minor-premise creeps (and vice versa); this distinction merely helps us differentiate, for instance, (a) sectarian creeps of a type satirized by Get Out, who may be sensitive to the major premise that all persons have equal moral worth (at least insofar as they would explicitly affirm it) but still be minor-premise creeps insofar as they do not recognize

23. Although mere social ignorance and moral insensitivity are importantly different, in practice, we often lack crucial contextual information necessary to sharply distinguish them.

24. Though you might not. The creeps, like many emotions and other attitudes, can be recalcitrant. We cannot say much about recalcitrance here, but see Calhoun (1984), D'Arms and Jacobson (2003), and Brady (2009). 
the personhood of particular black people ${ }^{25}$ and (b) major-premise psychopathic creeps who recognize their particular behavior as disrespectful-and choose it for that very reason.

\section{Objections and Responses}

One might object that the creeps is appropriate only when directed at morally ambiguous behavior or mild moral insensitivity, such as that of anti-social creeps, and not when directed at grotesque moral insensitivity. If so, then claiming that the creeps is appropriate in more extreme cases mistakenly inflates the concept of creepiness, and risks trivializing severe moral wrongs. Extremely dangerous or blameworthy activity, like that of génocidaires, one might insist, calls for more severe emotional responses than the creeps. Call this the conceptual inflation objection to our moral sensitivity account. ${ }^{26}$

We agree that the activity of criminal psychopaths and war criminals may call for indignation, outrage, fear, blame, and other emotional responses. But we deny that feeling the creeps in addition to such emotions would be unfitting. Perhaps intuitions conflict regarding extreme cases. But, we suggest, some of this objection's force may come from conflating fittingness and other standards of emotional appropriateness. For feeling the creeps can be morally or prudentially inappropriate even when it accurately represents its object and thus is fitting. We cannot enumerate all of the requirements for feeling the creeps appropriately, but in this section, we defend five important ones. The first two, we suggest, defuse the conceptual inflation objection. The remaining three defend the moral appropriateness of feeling the creeps against a separate argument, discussed below.

First, in some high-stakes situations, feeling the creeps (as opposed to, say, fear) might be prudentially inappropriate. In such moments, what demands attentive response may be danger, not moral insensitivity. But the source of danger might still be creepy, and if so, feeling the creeps later may be prudent. For instance, regardless of whether it would have been prudent for Trayvon Martin to have felt the creeps about George Zimmerman (a question we, the authors, cannot answer), prudence certainly does not forbid us from feeling the creeps about how Zimmerman pursued and killed Martin.

Second, feeling the creeps, even when it is fitting, might also be morally inappropriate. Plausibly, there is a moral norm that, ceteris paribus, when two morally critical emotions toward an object are fitting, and one cannot or should not

25. See Mills (1997) on how people of color regularly have been and still are regarded as "subpersons."

26. Thanks to Angela Smith for prompting this discussion. 
feel both simultaneously, one should feel that which embodies the more severe judgment. For instance, if Jeffrey Dahmer incessantly clicked a retractable pen while committing murder, it would be morally obscene to feel annoyance about the clicking rather than something much stronger about the murder. For that would imply (not logically, but informally) that the former is more significant. Similarly, feeling the creeps toward génocidaires may sometimes be morally inappropriate if it misdirects limited emotional attention toward their moral insensitivity and away from their crimes against humanity.

These two conditions reconcile the insight that motivates the conceptual inflation objection with our moral insensitivity account of the creeps' fittingness conditions. Feeling the creeps about extremely dangerous or blameworthy activity can be inappropriate. But it does not follow that feeling the creeps toward such activity is always inappropriate, nor that it is unfitting.

However, one might grant that the creeps is sometimes fitting (in the way we describe), yet insist that feeling it always demeans people, thereby treating them as though they are not full members of the community of moral agents. Regarding someone (even unconsciously) as insensitive to moral considerations might seem to inappropriately banish them, so to speak, from said community. ${ }^{27}$ People sometimes express this concern about attempts to achieve public ends that involve conveying experiences of the creeps. For example, this concern motivates some to criticize efforts to portray public figures accused of sexual assault or harassment as creeps in order to disempower them. Some objections to the mandatory registration of sex offenders also involve this concern. ${ }^{28}$ Call this the wrongful banishment objection.

However, feeling the creeps does not entail punishing or banishing (apparent) creeps. Even when the creeps is fitting, social sanction (not to mention banishment from the moral community) might still be morally or prudentially inappropriate. Instead, engaging with or simply fleeing the creep might be preferable, especially if evidence of their creepiness is scant.

That said, although we insist that there is sometimes sufficient evidence of moral insensitivity to (epistemically) justify feeling the creeps, we agree that feeling it without sufficient evidence may be morally objectionable. Morality requires us to regard others as full members of the moral community and as at least as morally sensitive as we regard ourselves, unless we have very good reason to do otherwise. On the other hand, the creeps' function as an involuntary early warning system can be highly valuable. As with any such system, false positives are often preferable to false negatives, especially in contexts of oppres-

27. See Carroll (1987: 57) on horror's geography: monsters often reside outside human communities. See also Mason (2003: 257-269).

28. Such concerns echo those considered regarding disgust and shame in Nussbaum (2010). For related discussion, see Alcoff (2018). 
sion. ${ }^{29}$ Thus, while extended observation of apparent creeps is sometimes impossible or imprudent, when reasonable, it provides some important protection against false positives. This provides a moral reason to avoid feeling the creeps impetuously and supplies a third requirement of appropriateness.

One might object that there can be no such moral requirement since one generally cannot choose to delay feeling an emotion. However, we assume that moral responsibility requires reasons-responsiveness, not volitional control (Smith 2005) - and the creeps is reasons-responsive. Even if feeling the creeps follows perception and initial judgment immediately, so too should its cessation follow reconsideration (emotional recalcitrance notwithstanding), as in Excused or Justified Subway. So, the lack of direct voluntary choice is no objection to this third requirement. ${ }^{30}$

The creeps' reasons-responsiveness also supplies a fourth requirement: in feeling the creeps, one should recognize the possibility of error and be open and responsive to new evidence. ${ }^{31}$ (More on this in Section 7.)

One might object that even with these caveats, the creeps is excessively judgmental. Feeling the creeps creates social distance between oneself and another by calling into question their moral agency. It thus seems to violate a duty to give people the benefit of the doubt or to foster community and mutual care. Feeling the creeps might be an anti-social activity in itself.

We share some of this concern, which points to a fifth way that feeling the creeps might be inappropriate, despite being fitting. Considerations about the value of community-building or helping creeps reform themselves sometimes provide sufficient reason not to feel the creeps, despite ample evidence of creepiness. Sometimes a therapeutic or objectifying stance is more appropriate.

However, it is also sometimes reasonable to exclude creeps from one's community, and it is typically reasonable to exclude them from one's society of intimates. One virtually never has any obligation to go on a second date with anyone, let alone a creep. Moreover, and especially regarding creeps who perpetuate oppressive practices, socio-historical context may supply reasons to be especially cautious about including creeps in one's community. Historically marginalized communities may sometimes be morally or prudentially justified in being more

29. As the MeToo movement has insisted, false negatives can be catastrophic. Daniel Ellsberg offers another important example of a false negative misdiagnosis involving Henry Kissinger, about whom he remarks, "the man who, with his boss [Nixon], has dropped more bombs than any human being in history, bugging and lying as necessary, is perceived as a peacemaker, as a lovable wit, a charming fellow, as anything but the murderous creep that he obviously is" (quoted in Wenner 1973). For a fictional example, the Armitages' performance of white innocence in Get Out (may) initially cause false negative misdiagnoses.

30. There are also good reasons to believe that we can exercise some voluntary control over the emotions we experience: see Roberts (2015).

31. For a similar claim, see Mason (2003: 253). 
reticent about welcoming members of oppressor communities who exhibit signs of creepiness.

Here, in summary, are five conditions that must be met for an instance of the creeps (even if fitting) to be morally and prudentially appropriate:

1. Feeling the creeps does not "swamp" (or distract one from feeling) another fitting emotion about something of greater prudential significance.

2. Feeling the creeps does not "swamp" (or distract one from feeling) another fitting emotion about something of greater moral significance.

3. One has a reasonable amount of evidence of the target person's creepiness.

4. One recognizes the possibility of error in identifying creepiness and is open and responsive to new evidence.

5. One lacks countervailing reasons for taking an objectifying or therapeutic stance toward the creep.

Although many instances of the creeps fail to meet these conditions, and so are inappropriate, it is a mistake to assume that feeling the creeps is always inappropriate. Creepy activity is morally serious, since it reflects radically misguided judgments about morality. Even if creeps cannot voluntarily control their creepiness, moral insensitivity involves agency insofar as it reflects assessments of the moral landscape. So, we can, in principle, legitimately ask creeps to justify their activities (whether mental or physical). We must not assume that creeps can never be morally responsible for their creepy activities, or that the problem is always in whoever feels the creeps. That said, we must strive to remedy the harms done by creepy activities, whether or not the creeps in question are morally responsible for them. And we must recognize creeps themselves as moral patients, questions about their moral agency notwithstanding.

Finally, even if they cannot directly control their moral insensitivity, treating creeps - or at least partial creeps - in ways that respond to how creepy they are respects their agency as partially or potentially not creeps. It respects them as people who could become more morally sensitive. Such treatment may involve simply feeling the creeps, but may involve more: judging that they are morally responsible, blaming them, expressing blame, conveying the creeps, or punishing them. 


\section{Epistemic Questions}

\subsection{Recognizing Creepiness}

Whether while watching a movie or "in the wild," properly registering creepiness by feeling the creeps is a morally significant achievement, since it requires sensitivity to insensitivity. ${ }^{32}$ (Recognizing one's own creepiness, not just others', is especially significant, morally and therapeutically. ${ }^{33}$ )

Because creepiness is a kind of insensitivity, creeps generally fail to recognize others' similar creepiness. This raises significant barriers to their recognizing prevalent forms of creepiness and makes it difficult for them to meet the epistemic appropriateness conditions (3) and (4) from Section 6. At the personal level, creeps seem more likely to befriend or identify with each other, since their creepiness is unlikely to be a barrier to their friendship, as it would likely be for non-creeps. Also, children may have trouble recognizing the creepiness of authority figures who habituate them into shared moral insensitivity. At the systemic level, creepiness in society's basic structure and popular media also inculcates and obscures creepiness via status quo bias and other mechanisms. 34 Consequently, insensitivity to certain moral considerations often seems appropriate to creeps - and sensitivity seems ridiculous, perverse, or ominous, and thus they resist it. 35

For instance, in a society that inculcates insensitivity to women's autonomy, it is an achievement to recognize anti-woman creeps as creeps rather than, say, "good ol' boys" or "awesome guys." Many people in such societies will not feel the creeps toward such creeps and will regard those who do as perversely moralistic or degenerate (e.g., as "femi-Nazis," "soy boys," "pussies," or "social justice warriors")..$^{36}$

Hence emotional "consciousness raising" is sometimes required to recognize the creepiness of, for instance, sexual harassment, and we cannot simply take the creeps (or the lack thereof) as a perfectly trustworthy source of information about what is morally salient. We must think critically to determine when the

32. Though we do not defend these claims here, we think that appropriately feeling the creeps is required for full moral understanding of creepy activity and provides evidence of decent moral character. For these two claims, with respect to emotions generally, see Starkey (2008) and Taylor (1975), respectively.

33. See Yancy's (2015) confessions regarding sexism, and Klein (2018).

34. There is likely significant cultural variation in what people regard as creepy. One of us, an American traveling in Morocco years ago, found it creepy to see café upon café with only male patrons - but many locals probably did not.

35. Thus, inquiries into creepiness are relevant to the epistemology of ignorance. See Sullivan and Tuana (2007).

36. See Roberts-Cady (2017) for more on normalization. 
creeps is fitting. But how does one discern whether the creeps is fitting if one has not been socialized to feel the fitting creeps, nor to think critically about creepiness? How can one cultivate a tendency to feel the creeps properly?

First, one should look out for moral insensitivity, just as one looks for other morally salient features of one's landscape. Our examples suggest that, whenever possible, this process should involve listening to and learning from people who have persistently felt the creeps, especially members of historically marginalized groups. However, we should not listen uncritically: some people who often feel the creeps may do so unfittingly, merely reflecting contempt toward or suspicion of people who differ from them. Given the gendered and classist nature of common narratives about creepiness, we worry that some highly privileged women may be socialized to feel the creeps often and easily, even when it is unfitting and inappropriate.

If one does not know it when one sees it, perhaps the best technique for recognizing creepiness is inference to the best explanation. For example, Carnists (the case of the vegan who observes people eating turkeys' legs at the carnival) involves people who relish adhering to popular culinary norms even though, in the age of industrialized farming, doing so causes great cruelty and generates well-known, though not widespread, outrage. One explanation of this exuberant carnist activity is insensitivity to the moral considerations that make eating animals prima facie wrong. Alternatively, one might explain it in terms of active or passive ignorance of the extent of the pain and death involved in torturing and killing tens of billions of land animals and hundreds of billions of sea creatures annually. To decide between these and other possible explanations, it may help to observe the extent of the carnist's moral sensitivity toward humans and nonhuman animals not customarily treated as meat. 37

Another possible explanation, sure to be considered by carnists, is that carnists are morally sensitive, vegan objections notwithstanding. In The Lives of Animals, J. M. Coetzee dramatizes the struggle to find the best explanation of such fundamental conflicts of moral judgment and feeling in the character of a zealous vegan who visits her condescending adult carnist son and his equally dismissive spouse. While driving her to the airport, Elizabeth's son says, "I haven't had time to make sense of why you have become so intense about the animal business." The novella's final conversation continues thus:

"A better explanation," she says, "is that I have not told you why, or dare not tell you. When I think of the words, they seem so outrageous that

37. On linked moral insensitivity regarding animals and women, see Adams (1990). Assessing the moral insensitivity of carnists who neither participate in nor benefit from industrialized food production depends on answering many different questions. 
they are best spoken into a pillow or into a hole in the ground, like King Midas."

"I don't follow. What is it you can't say?"

"It's that I no longer know where I am. I seem to move around perfectly easily among people, to have perfectly normal relations with them. Is it possible, I ask myself, that all of them are participants in a crime of stupefying proportions? Am I fantasizing it all? I must be mad! Yet every day I see the evidences. The very people I suspect produce the evidence, exhibit it, offer it to me. Corpses. Fragments of corpses that they have bought for money.

"It is as if I were to visit friends, and to make some polite remark about the lamp in their living room, and they were to say, 'Yes, it's nice, isn't it? Polish-Jewish skin it's made of, we find that's best, the skins of young Polish-Jewish virgins.' And then I go to the bathroom and the soap-wrapper says, 'Treblinka-100\% human stearate.' Am I dreaming, I say to myself? What kind of house is this?

“Yet I'm not dreaming. I look into your eyes, into Norma's, into the children's, and I see only kindness, human-kindness. Calm down, I tell myself, you are making a mountain out of a molehill. This is life. Everyone else comes to terms with it, why can't you? Why can't you?" (Coetzee 1999: 69)

Elizabeth sees in her son's family evidence of moral sensitivity and moral depravity. She questions whether her emotions are best explained by her own extreme moral error or their extreme creepiness. This struggle with emotional ambivalence disorients her profoundly. Because feeling the creeps reflects judgments about basic moral considerations, the disposition to experience it fundamentally orients one's moral sensibilities and even one's self. This partly explains why disagreement about creepiness can be so intractable.

It also helps explain why growing social awareness of creepiness takes considerable time, and why the strangeness of disagreement about obvious, profound moral errors is sometimes most easily appreciated regarding the distant past. As Kwame Appiah (2010) asks regarding chattel slavery, lynching, and the denial of women's rights, "Looking back at such horrors, it is easy to ask: What were people thinking?" 38 This is the quintessential puzzle about creeps: how generally sensible, even kind people can be so morally insensitive.

38. In Appiah's view, and ours, industrial animal slaughter is a leading contender for future widespread retrospective moral horror. 


\subsection{Conveying, Extirpating, and Inculcating the Creeps}

Overcoming the distinctive epistemic obstacles to recognizing creepiness requires emotionally laden communication. Successfully communicating about the creeps creates a shared moral understanding of creepiness. ${ }^{39}$ Such communication is especially important for inculcating proper emotional dispositions in children.

Portraying creepy events and people as sad, gross, or enraging is neither necessary nor sufficient for conveying their creepiness. It is unnecessary because feeling or conveying anger toward creeps is sometimes unfitting. For creepy behavior is not always wrong; furtively peering around corners might evince moral insensitivity even when it does no wrong. Nor is creepy behavior always sad or gross.

To see that it's insufficient, consider that conveying anger, blame, or rage toward cannibal serial killer Jeffrey Dahmer need not involve or convey the creeps. In feeling the creeps, you respond to his moral depravity, which may lie beyond blame's reach. For we suspect that (1) total creeps-like criminal psychopathsare sometimes not responsible for their creepiness, and (2) blame at most reaches what one is morally responsible for. When someone is at most tenuously morally responsible for their evil, there may be nothing for us to feel or express except terror, pity - and the creeps.

Since sometimes the creeps should be felt and conveyed, extirpation of the fitting creeps can be both morally inappropriate and also itself creepy insofar as it undermines emotional barriers to becoming a creep. Public relations efforts designed to help children overcome their unease about eating animals-such as clowns who promote eating hamburgers, cartoon cows who urge us to eat chickens, and language that obscures the link between what kids find on their plates and the living animals they adore (e.g., "pork," not "pigs") - are especially creepy, being akin to propaganda designed to extinguish our moral repulsion to racist or xenophobic atrocities.

Inculcation of the creeps can also be morally inappropriate when the emotion is unfitting. For example, anti-abortion activists often portray abortion as creepy. A newspaper article about efforts to close Kentucky's only abortion clinic quotes an observer who describes anti-abortion protests as follows: "There are the Catholics who stand vigil, saying the rosary while lining both sides of the sidewalk to create an 'eerie and disconcerting' gauntlet for patients to run" (Smith 2017). Such theatrics aim to instill the creeps about abortion clinics but

39. For an appalling example of a failure to do so, consider Elizabeth's son's response to her anguished query about her inability to accept carnism as others do: "He inhales the smell of cold cream, of old flesh. 'There, there,' he whispers in her ear. 'There, there. It will soon be over"' (Coetzee 1999: 69). 
are themselves creepy. For, seeking or providing an abortion (even if it is wrong) is not evidence of moral insensitivity, since people typically give the matter serious moral consideration. However, regarding people who seek or provide abortions as necessarily morally insensitive is itself badly morally mistaken.

\section{Conclusion}

Many questions about the creeps, creepy activities, and creepy people remain. First, does the mode of portrayal matter for conveying how creepy some person or practice is? For example, we suspect that graphic displays of factory farms' and slaughterhouses' customary violence (e.g., in the documentaries Earthling and Dominion) are especially conducive to eliciting the creeps toward eating animals. If so, what does that entail about creepiness or our capacity for moral sensitivity?

Second, why does creepiness so often accompany oppression? Is it because oppression provides social permission to creeps? Because oppression renders some people relatively powerless, which creeps can easily exploit? Because the generalizing and stereotyping common in human cognition conduce to sectarian moral insensitivity? Or perhaps because political and economic structures incentivize it?

Third, what can individuals and groups do to prevent creepiness in themselves and others? Relatedly, how should the public respond to and prevent creepy institutional behavior, especially regarding "big data" (Tene \& Polonetsky 2013)? May institutions ever justly allow (or, as with publicly traded forprofit firms, require) moral insensitivity?

Fourth, how, besides by feeling the creeps, should one respond to creeps? Attempts to persuade, blame, punish, or reform might not be sensibly directed at people who entirely lack moral sensitivity, and full-blown creeps might not be moral agents at all. So, it is an open question whether and when any of these responses is advisable.

That raises a final, more fundamental question: does moral insensitivity always involve the sort of activity required for moral responsibility? If not, then under what conditions are creeps morally responsible (and so potentially blameworthy) for their creepy activity?

However we answer these questions, our treatment of creeps must be more humane than the, shall we say, undiplomatic treatment typically given to biological monsters in horror movies, who are generally killed by vigilantes. Even the creepiest of creeps deserve better than that. 


\section{Acknowledgements}

The authors are grateful for helpful feedback from Tyler Doggett, Holly Jones, Robert Mason, Jen Rowland, Emily Rutter, Elizabeth Scarbrough, Angela Smith, Juli Thorson, Sarah Vitale, the students in Rachel's 2019 Emotions, Character, and Moral Responsibility class at BSU, anonymous referees at other journals who helped us improve the paper, and three anonymous referees at Ergo.

\section{References}

Adams, Carol (1990). The Sexual Politics of Meat. Continuum.

Alcoff, Linda Martín (2018, May 16). This Is Not Just about Junot Díaz. New York Times. Retrieved from https://www.nytimes.com/2018/05/16/opinion/junot-diaz-metoo. html.

Appiah, Kwame Anthony (2010, September 26). What Will Future Generations Condemn Us For? The Washington Post. Retrieved from http://www.washingtonpost. com/wp-dyn/content/article/2010/09/24/AR2010092404113_pf.html.

Arpaly, Nomy and Timothy Schroeder (2014). In Praise of Desire. Oxford University Press.

Baldwin, James (1985). Introduction: The Price of the Ticket. In The Price of the Ticket: Collected Nonfiction, 1948-1985 (ix-xx). St. Martin's Press.

Brady, Michael (2009). The Irrationality of Recalcitrant Emotions. Philosophical Studies, 145(3), 413-430. https://doi.org/10.1007/s11098-008-9241-1

Calhoun, Cheshire (1984). Cognitive Emotions? In Cheshire Calhoun and Robert Solomon (Eds.), What Is an Emotion? Classic Readings in Philosophical Psychology (327-342). Oxford University Press.

Carroll, Noël (1987). The Nature of Horror. The Journal of Aesthetics and Art Criticism, 46(1), 51-59. https://www.jstor.org/stable/431308?seq=1\#metadata_info_tab_con tents

Coetzee, J. M. (1999). The Lives of Animals. Princeton University Press.

D'Arms, Justin and Daniel Jacobson (2000). The Moralistic Fallacy: On the 'Appropriateness' of Emotions. Philosophy and Phenomenological Research, 61(1), 65-90. https://doi.org/10.2307/2653403

D'Arms, Justin and Daniel Jacobson (2003). The Significance of Recalcitrant Emotions (or, Anti-Quasijudgmentalism). Royal Institute of Philosophy Supplement, 52, 127-145. https://doi.org/10.1017/s1358246100007931

Deonna, Julien and Fabrice Teroni (2012). The Emotions: A Philosophical Introduction. Routledge.

Draeger, John (2011). What Peeping Tom Did Wrong. Ethical Theory and Moral Practice, 14(1), 41-49. https://doi.org/10.1007/s10677-010-9225-z

Du Bois, W. E. B. (2007). The Souls of Black Folk. Oxford University Press. (Original work published 1903)

Frijda, Nico, Peter Kuipers, and Elisabeth ter Schure (1989). Relations Among Emotion, Appraisal, and Emotional Action Readiness. Journal of Personality and Social Psychology, 57(2), 212-228. https://doi.org/10.1037/0022-3514.57.2.212

Haidt, Jonathan, Paul Rozin, Clark Mccauley, and Sumio Imada (1997). Body, Psyche, 
and Culture: The Relationship between Disgust and Morality. Psychology and Developing Societies, 9(1), 107-131. https://doi.org/10.1177/097133369700900105

Joy, Melanie (2009). Why We Love Dogs, Eat Pigs, and Wear Cows: An Introduction to Carnism. Conari Press.

Kelly, Daniel (2013). Yuck! The Nature and Moral Significance of Disgust. MIT Press.

Klein, Avi (2018, June 30). What Men Say about MeToo in Therapy. The New York Times. Retrieved from https://www.nytimes.com/2018/06/30/opinion/sunday/men-metootherapy-masculinity.html

Kotsko, Adam (2015). Creepiness. Zero Books.

Lifton, Robert Jay (2000). The Nazi Doctors: Medical Killing and the Psychology of Genocide. Basic Books.

Mason, Michelle (2003). Contempt as a Moral Attitude. Ethics, 113(2), 234-272. https:// doi.org/10.1086/342860

McAndrew, Francis and Sara Koehnke (2016). On the Nature of Creepiness. New Ideas in Psychology, 43, 10-15. https://doi.org/10.1016/j.newideapsych.2016.03.003

Menninghaus, Winfried, Valentin Wagner, Julian Hanich, Eugen Wassiliwizky, Thomas Jacobsen, and Stefan Koelsch (2017). The Distancing-Embracing Model of the Enjoyment of Negative Emotions in Art Reception. Behavioral and Brain Sciences, 40(E347), 1-15. https://doi.org/10.1017/s0140525x17000309

Mills, Charles (1997). The Racial Contract. Cornell University Press.

Moore, Roger (2012). A Bayesian Explanation of the 'Uncanny Valley' Effect and Related Psychological Phenomena. Scientific Reports, 2(864), 1-5. https://doi.org/10.1038/ srep00864

Mori, Masahiro (2012). The Uncanny Valley (Karl MacDorman and Norri Kageki, Trans.). IEEE Robotics \& Automation Magazine, 19(2), 98-100. (Original work published 1970) https://doi.org/10.1109/mra.2012.2192811

Nussbaum, Martha (2010). From Disgust to Humanity: Sexual Orientation and Constitutional Law. Oxford University Press.

Plakias, Alexandra (2018). The Response Model of Moral Disgust. Synthese, 195(12), 5453-5472. https://doi.org/10.1007/s11229-017-1455-3

Roberts, Tom (2015). Emotional Regulation and Responsibility. Ethical Theory and Moral Practice, 18(3), 487-500. https://doi.org/10.1007/s10677-014-9535-7

Roberts-Cady, Sarah (2017). Exploring Eco-Ability: Reason and Normalcy in Ableism, Speciesism, and Ecocide. In Anthony J. Nocella II, Amber E. George, and J. L. Schatz, (Eds.), The Intersectionality of Critical Animal, Disability, and Environmental Studies: Toward Eco-Ability, Justice and Liberation (99-114). Lexington Books.

Roseman, Ira, Cynthia Wiest, and Tamara Swartz (1994). Phenomenology, Behaviors, and Goals Differentiate Discrete Emotions. Journal of Personality and Social Psychology, 67(2), 206-221. https://doi.org/10.1037/0022-3514.67.2.206

Rozin, Paul, Lily Guillot, Katrina Fincher, Alexander Rozin, and Eli Tsukayama (2013). Glad to Be Sad, and Other Examples of Benign Masochism. Judgment and Decision Making, 8(4), 439-447. https://digitalcommons.wcupa.edu/cgi/viewcontent.cgi?artic le $=1025 \&$ context $=$ musichtc_facpub

Rozin, Paul, Maureen Markwith, and Caryn Stoess (1997). Moralization and Becoming a Vegetarian: The Transformation of Preferences into Values and the Recruitment of Disgust. Psychological Science, 8(2), 67-73. https://doi.org/10.1111/j.1467-9280.1997. tb00685.x 
Rozin, Paul and Leher Singh (1999). The Moralization of Cigarette Smoking in the United States. Journal of Consumer Psychology, 8(3), 321-337. https://doi.org/10.1207/ s15327663jcp0803_07

Seyama, Jun'ichiro and Ruth Nagayama (2007). The Uncanny Valley: Effect of Realism on the Impression of Artificial Human Faces. Presence: Teleoperators and Virtual Environments, 16(4), 337-351. https://doi.org/10.1162/pres.16.4.337

Smith, Angela (2005). Responsibility for Attitudes: Activity and Passivity in Mental Life. Ethics, 115(2), 236-271. https://doi.org/10.1086/426957

Smith, Jordan (2017, October 17). Kentucky's Last Remaining Abortion Clinic Could Be Forced to Shut Its Doors. The Intercept. Retrieved from https://theintercept. com/2017/10/17/kentucky-last-abortion-clinic-emw/

Starkey, Charles (2008). Emotion and Full Understanding. Ethical Theory and Moral Practice, II(4), 425-454. https://doi.org/10.1007/s10677-007-9103-5

Sullivan, Shannon and Nancy Tuana (Eds.) (2007). Race and Epistemologies of Ignorance. SUNY Press.

Taylor, Gabriele (1975). Justifying the Emotions. Mind, 84(335), 390-402. https://academic.oup.com/mind/article/LXXXIV/1/390/1155817

Tene, Omer and Jules Polonetsky (2013). A Theory of Creepy: Technology, Privacy and Shifting Social Norms. Yale Journal of Law \& Technology, 16(1), 59-102. https://digitalcommons.law.yale.edu/cgi/viewcontent.cgi?article=1098\&context=yjolt

Watt, Margo, Rebecca Maitland, and Catherine Gallagher (2017). A Case of the 'Heeby Jeebies': An Examination of Intuitive Judgements of 'Creepiness.' Canadian Journal of Behavioural Science, 49(1), 58-69. https://doi.org/10.1037/cbs0000066

Watson, Gary (1987). Responsibility and the Limits of Evil: Variations on a Strawsonian Theme. In Ferdinand Schoeman (Ed.), Responsibility, Character and the Emotions (256286). Cambridge University Press. https://doi.org/10.1017/cbo9780511625411.011

Wenner, Jann. (1973, November 8). Daniel Ellsberg: The Rolling Stone Interview. Rolling Stone Magazine. Retrieved from https://www.rollingstone.com/politics/politicsnews/daniel-ellsberg-the-rolling-stone-interview-185965/

Williams, Bernard (1985). Ethics and the Limits of Philosophy. Harvard University Press.

Woomer, Lauren (2019). Agential Insensitivity and Socially Supported Ignorance. Episteme, 16(1), 73-91. https://doi.org/10.1017/epi.2017.28

Yancy, George (2015, December 24). Dear White America. The New York Times. Retrieved from https://opinionator.blogs.nytimes.com/2015/12/24/dear-white-america/ 